\title{
The Job Demands-Resources model: Challenges for future research
}

\author{
Authors: \\ Evangelia Demerouti ${ }^{1}$ \\ Arnold B. Bakker ${ }^{2}$ \\ Affiliations: \\ ${ }^{1}$ Eindhoven University of \\ Technology, Department of \\ Industrial Engineering and \\ Innovation Sciences, The \\ Netherlands \\ ${ }^{2}$ Erasmus University \\ Rotterdam, Department of \\ Work and Organisational \\ Psychology, Rotterdam, The \\ Netherlands \\ Correspondence to: \\ Evangelia Demerouti \\ Email: \\ e.demerouti@tue.nl \\ Postal address: \\ PO Box 513, 5600 MB \\ Eindhoven, The Netherlands \\ How to cite this article: \\ Demerouti, E., \& Bakker, A.B. \\ (2011). The Job Demands- \\ Resources model: Challenges \\ for future research. SA \\ Journal of Industrial \\ Psychology/SA Tydskrif vir \\ Bedryfsielkunde, 37(2), Art. \\ \#974, 9 pages. doi:10.4102/ \\ sajip.v37i2.974
}

C 2011. The Authors

Licensee: OpenJournals

Publishing. This work

is licensed under the

Creative Commons

Attribution License.
Motivation: The motivation of this overview is to present the state of the art of Job DemandsResources (JD-R) model whilst integrating the various contributions to the special issue.

Research purpose: To provide an overview of the JD-R model, which incorporates many possible working conditions and focuses on both negative and positive indicators of employee well-being. Moreover, the studies of the special issue were introduced.

Research design: Qualitative and quantitative studies on the JD-R model were reviewed to enlighten the health and motivational processes suggested by the model.

Main findings: Next to the confirmation of the two suggested processes of the JD-R model, the studies of the special issue showed that the model can be used to predict work-place bullying, incidences of upper respiratory track infection, work-based identity, and early retirement intentions. Moreover, whilst psychological safety climate could be considered as a hypothetical precursor of job demands and resources, compassion satisfaction moderated the health process of the model.

Contribution/value-add: The findings of previous studies and the studies of the special issue were integrated in the JD-R model that can be used to predict well-being and performance at work. New avenues for future research were suggested.

Practical/managerial implications: The JD-R model is a framework that can be used for organisations to improve employee health and motivation, whilst simultaneously improving various organisational outcomes.

\section{Introduction}

The Job Demands-Resources (JD-R) model is a theoretical framework that tries to integrate two fairly independent research traditions: the stress research tradition and the motivation research tradition. According to the JD-R model, job demands are initiators of a health impairment process and job resources are initiators of a motivational process. In addition, the model specifies how demands and resources interact, and predict important organisational outcomes. Previous research has shown that the assumptions of the model hold not only for self-reports but also for objective data. Moreover, studies have shown that the JD-R model can predict the experience of burnout and of work engagement (e.g. Demerouti, Bakker, Nachreiner \& Schaufeli, 2001; Schaufeli \& Bakker, 2004). However, there are still several open questions related to the processes postulated in the model.

The purpose of this special issue is to bring together innovative studies on the JD-R model, which is relevant for both individuals and organisations at large. We were particularly interested in theory-guided studies that focus on the health impairment and motivational processes as well as possible moderators and mediators (cultural, organisational, and individual characteristics) of these processes. To a large extent this objective was achieved as we received a variety of submissions that add to our knowledge in several respects. The aim of the present editorial paper is threefold. First we will introduce the model. As a second step we will discuss several issues that to our opinion are essential for future research and practice related to the model. Finally, the editorial will end with an introduction of the different studies included in this special issue.

\section{The Job Demands-Resources model}

The main assumption of the Job Demands-Resources (JD-R) model (Bakker \& Demerouti, 2007; Bakker, Demerouti, De Boer \& Schaufeli, 2003a; Bakker, Demerouti, Taris, Schaufeli \& Schreurs, 2003b; Demerouti, Bakker, Nachreiner \& Schaufeli, 2001) is that every occupation has its own 
specific risk factors associated with job-related stress. These factors can be classified in two general categories (i.e. job demands and job resources), thus constituting an overarching model that may be applied to various occupational settings, irrespective of the particular demands and resources involved. Job demands refer to those physical, psychological, social, or organisational aspects of the job that require sustained physical and/or psychological (cognitive and emotional) effort or skills and are therefore associated with certain physiological and/or psychological costs. Examples include high work pressure, an unfavourable physical environment and irregular working hours. Although job demands are not necessarily negative, they may turn into job stressors when meeting those demands require high effort from which the employee fails to recover adequately (Meijman \& Mulder, 1998).

Job resources refer to those physical, psychological, social, or organisational aspects of the job that are either/or:

1. functional in achieving work goals

2. reduce job demands and the associated physiological and psychological costs

3. stimulate personal growth, learning, and development.

Hence, resources are not only necessary to deal with job demands, but they also are important in their own right. This corresponds with Hackman and Oldham's (1980) job characteristics model that emphasises the motivational potential of job resources at the task level, including autonomy, feedback, and task significance. In addition, this agrees on a more general level with conservation of resources (COR) theory (Hobfoll, 2001) that states that the prime human motivation is directed towards the maintenance and accumulation of resources. Accordingly, resources are valued in their own right or because they are means to achieve or protect other valued resources. Job resources may be located at the macro, organisational level (e.g. salary or wages, career opportunities, job security), the interpersonal level (e.g. supervisor and coworker support, team climate), the specific job position (e.g. role clarity, participation in decision making), and at the level of the task (e.g. skill variety, task identity, task significance, autonomy, and performance feedback).

\section{Dual processes}

A second premise of the JD-R model is that two different underlying psychological processes play a role in the development of job-related strain and motivation (see Figure 1). The first is a process of health impairment, which suggests that demanding jobs or jobs with chronic job demands (e.g. work overload, emotional demands) exhaust employees' mental and physical resources and may therefore lead to the depletion of energy (i.e. a state of exhaustion) and to health problems (e.g. general health and repetitive strain injury) (Bakker, Demerouti, \& Schaufeli, 2003; Demerouti et al., 2000, 2001; Leiter, 1993). According to Hockey (1993), individuals use performance-protection strategies under the influence of environmental demands. Such strategies are the mobilisation of sympathetic activation (autonomic and endocrine) and increased subjective effort (use of active control in information processing). Even though the use of these strategies may inhibit decrements in primary task performance, according to Hockey's theory, indirect degradation may be identified. Such degradation may take the form of strategy adjustments (narrowing of attention, increased selectivity, redefinition of task requirements), and fatigue after-effects (risky choices, high levels of subjective fatigue). The long-term effect of such compensatory strategies may be a draining of an individual's energy, which could eventually result in a breakdown.

The second process proposed by the JD-R model is motivational in nature, whereby it is assumed that job resources have motivational potential and lead to high work engagement, low levels of cynicism and excellent performance (see also Figure 1). As follows from our definition, job resources may play an intrinsic motivational role because they foster employees' growth, learning and development, or they may play an extrinsic motivational role because they are instrumental in achieving work goals. In the former case, job resources fulfil basic human needs (Deci \& Ryan, 1985), such as the needs for autonomy (DeCharms, 1968), competence (White, 1959), and relatedness (Baumeister \& Leary, 1995). For instance, proper feedback fosters learning, thereby increasing job competence, whereas decision latitude and social support satisfy the need for autonomy and the need to belong, respectively (see Van den Broeck, Vansteenkiste, De Witte \& Lens, 2008). Job resources may also play an extrinsic motivational role, because, according to the effort-recovery model (Meijman \& Mulder, 1998), work environments that offer many resources foster the willingness to dedicate one's efforts and abilities to the work task. In such a case it is likely that the task will be completed successfully and that the work goal will be attained. For instance, supportive colleagues and proper feedback from one's superior increase the likelihood of being successful in achieving one's work goals. In either case, be it through the satisfaction of basic needs or through the achievement of work goals, the presence of job resources leads to engagement, whereas their absence evokes a cynical attitude towards work (see Figure 1; Demerouti et al., 2001; Lewig, Xanthopoulou, Bakker, Dollard, \& Metzer, 2007; Schaufeli, Bakker \& Van Rhenen, 2009).

\section{Interactions between job demands and resources}

Next to the suggested main effects of job demands and resources, the JD-R model proposes that the interaction between job demands and job resources is important for the development of job strain and motivation. Inherent in the definition of job resources is the assumption that these resources may buffer the impact of job demands on job strain, including burnout (Bakker, Demerouti, \& Euwema, 2005; Bakker et al., 2003b; Xanthopoulou et al., 2007b). The buffering role of job resources is consistent with the DemandControl Model (DCM; Karasek, 1998) and the Effort-Reward Imbalance Model (ERIM; Siegriest, 1996). Whereas the DCM states that control over the execution of tasks (autonomy) may buffer the impact of work overload on job stress; and the ERIM states that rewards may minimise the unfavourable 


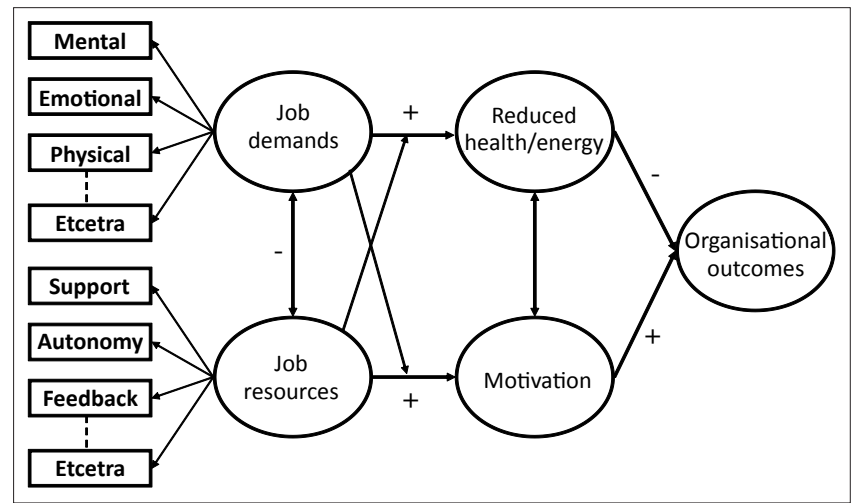

FIGURE 1: Two different underlying psychological processes play a role in the development of job-related strain and motivation.

effects of effort expedition, the JD-R model expands these views and states that different types of job demands and job resources may interact in predicting job strain. Which job demands and resources play a role in a certain organisation and a certain job function depends upon the specific job characteristics.

The buffer hypothesis is consistent with Kahn and Byosiere (1992), who argue that the buffering or interaction effect can occur between any pair of variables in the stress-strain sequence. They claim that properties of the work situation, as well as characteristics of the individual, can buffer the effects of a stressor. The buffering variable can reduce the tendency of organisational properties to generate specific stressors, alter the perceptions and cognitions evoked by such stressors, moderate responses that follow the appraisal process, or reduce the health-damaging consequences of such responses (Kahn \& Byosiere, 1992, p. 622).

The final and more recent fourth proposition of the JD-R model is that job resources particularly influence motivation or work engagement when job demands are high. This represents the so-called coping hypothesis (Bakker, Hakanen, Demerouti \& Xanthopoulou, 2007; Bakker, Van Veldhoven \& Xanthopoulou 2010; Hakanen, Bakker, \& Demerouti, 2005). To illustrate, Bakker et al. (2007) tested this hypothesis in a sample of Finnish teachers. It was predicted and found that job resources are most beneficial in maintaining work engagement under conditions of high job demands (e.g. pupil misbehaviour). For example, innovativeness, appreciation, and positive organisational climate boosted work engagement particularly when pupil misbehaviour was high. Similarly, Bakker et al. (2010) tested in a large heterogeneous sample of employees whether work attitudes (task enjoyment and organisational commitment) are most positive when job demands and job resources are both high. Results of moderated structural equation modelling analyses provided strong support for the hypothesis: 15 of the 16 hypothesised interactions were significant for task enjoyment and 13 of the 16 interactions were significant for organisational commitment. Job resources (skill utilisation, learning opportunities, autonomy, colleague support, leader support, performance feedback, participation in decision making, and career opportunities) predicted task enjoyment and organisational commitment particularly under conditions of high job demands (workload and emotional demands). This indicates that resources become most salient under demanding conditions. In other words, there is a need for a challenge (i.e. a demanding condition) in order for job resources to be translated into task enjoyment and work engagement. This is in line with Hobfoll (2002) who has argued that resource gain in itself has only a modest effect, but instead acquires its saliency in the context of resource loss. This implies that job resources gain their motivational potential particularly when employees are confronted with high job demands. In other words, the coping hypothesis suggests that under stressful conditions individuals will be more like to use resources as a coping mechanism or stressreducing action.

\section{Challenges for future research Personal resources}

An important extension of the JD-R model is the inclusion of personal resources. Xanthopoulou, Bakker, Demerouti and Schaufeli (2007) examined the role of three personal resources (self-efficacy, organisational-based self-esteem and optimism) in predicting exhaustion and work engagement. Results of structural equation modeling analyses showed that personal resources did not manage to offset the relationship between job demands and exhaustion. In contrast, personal resources were found to partly mediate the relationship between job resources and work engagement, suggesting that job resources foster the development of personal resources. Also the longitudinal study by Xanthopoulou et al. (2009) suggested that personal resources were reciprocal with job resources and work engagement over time. Thus, job resources predict personal resources and work engagement; and personal resources and work engagement, in turn, predict job resources. Although we do have evidence that personal resources can be conceptualised as mediator or outcome in the JD-R model, we expect that they might have an even more complex role in modifying the impact of the work environment into positive or negative outcomes. If we turn back to stress research, Lazarus and Folkman (1984) argued that people suffer from stress when they believe they lack the resources to deal with difficult events. They also noted the complex interaction between individuals and their environment and emphasised the role of cognitive processes and individual characteristics (such as appraisal and coping) that may affect the outcome of potentially stressful events. Illustrative of this idea is the study conducted by Riolli and Savicki (2003). These authors showed that information service workers' personal resources like optimism were particularly beneficial when work resources were low. Other researchers have recognised additional factors that may affect stress, such as personality dimensions (Costa \& McCrae, 1990). Avey, Luthans and Jensen (2009) suggest that psychological capital (i.e. the personal resources of self-efficacy, hope, optimism, and resilience) may be the key to understanding the variation in perceived symptoms of stress, as well as intentions to quit and job search behaviours better. Future research should therefore examine whether the complex interaction of 
individual resources with the work environment may take the form of three-way interactions between job demands, job resources, and personal resources so that personal resources qualify the two-way interactions between job demands and job resources. Thus, we propose that employees may be particularly at risk for burnout if confronted with high job demands and low job resources and if their personal resources - such as self-efficacy and optimism - are low. In addition, employees may be particularly engaged in their work and flourish if job demands and job resources are high, and if their personal resources - such as resilience and hope - are high as well.

\section{Job demands as challenge and hindrance stressors}

Job demands are defined as aspects of work that require effort and therefore are associated with costs. Although this definition does not imply that demands are necessarily bad, within the JD-R model the main role of demands is seen in the health impairment process. Recently, LePine, Podsakoff and LePine (2005) and Podsakoff et al. (2007) made a distinction between challenge stressors and hindrance stressors. Hindrance job stressors are defined as job demands or work circumstances that involve excessive or undesirable constraints that interfere with or inhibit an individual's ability to achieve valued goals (Cavanough et al., 2000). This description is very similar to the definition of job demands within the JD-R model. Examples of hindrance job demands are role conflict, role overload, and role ambiguity. These job stressors are considered as 'bad'. Stressors are defined as challenging when potentially promoting the personal growth and achievement of the employee (Podsakoff et al., 2007), which demonstrates a high similarity to the definition of job resources as stated in the JD-R model. Examples of challenge stressors are high levels of workload, time pressure, and responsibility (McCauley, Ruderman, Ohlott, \& Marrow, 1994), which represent examples of job demands within the JD-R model. These demands have the potential to be seen as rewarding work experiences well worth the discomfort involved, and are therefore considered as 'good' stressors.

Van den Broeck, De Cuyper, De Witte, and Vansteenkiste, M. (in press) integrated the differentiation between job hindrances and job challenges in the JD-R model. Results of confirmatory factor analyses supported the differentiation between the two types of demands and job resources in two samples $\left(N_{1}=261\right.$ and $\left.N_{2}=441\right)$. Further, structural equation modeling confirmed the hypotheses that job hindrances associate positively with exhaustion and negatively with vigour. Job resources displayed the reversed pattern of relations. Job challenges were unrelated to exhaustion and positively related to vigour.

Whether the differentiation between challenge and hindrance demands is valid is still unknown as there is not sufficient empirical evidence on this issue. Moreover, whether the differentiation between these two kinds of demands is valid for every job is still an unclear issue. It is, for instance, possible that high cognitive load is motivating for an academic job but demanding for a designer. Therefore, more research is necessary to clarify the role of the specific demands within the JD-R. To answer this question, it seems important to investigate various different jobs, using various measurement instruments for the demands and several measurement points (as finding a cross-sectional correlation has implications that are different from finding a lagged effect).

\section{Integrating multilevel constructs in the JD-R Model}

As scholars recognise that organisations are complex constellations consisting of different structural, functional or hierarchical levels, it is not surprising that organisational researchers have conceptualised several multilevel constructs, namely constructs that are meaningful across multiple levels of analysis. For instance, Lindsley, Brass and Thomas (1995) have conceptualised efficacy beliefs at the individual, group and organisational level and hypothesised that efficacy beliefs and performance are related in a similar way across levels. Other examples of multilevel constructs include affect (George, 1990) and creativity (Drazin, Glynn \& Kazanjian, 1999). Advantages of integrating multilevel constructs in research are that they can help to capture the complexity of organisational phenomena and develop more sophisticated theoretical models. Chen, Mathieu and Bliese suggest that:

... whenever researchers aggregate data over one or more facets (e.g. items, time, people, units) they must justify the procedure in terms of establishing an alignment between the nature of the construct, its measurement, and its analysis vis-à-vis other constructs of interests.

(Chen et al., 2004, p. 275)

Whilst research on the JD-R model has been exclusively at the individual level, there are some attempts to integrate other levels of analysis as well. The first study on the JD-R model (Demerouti et al., 2001) tested the assumptions of the model on the individual level using self-report data and on the job function level using observer ratings for job demands and job resources and averaged scores (at the group level) for burnout. This study found similar relationships for both the individual and the group level. Moreover, individual scores on job demands and job resources as well as their outcomes have been used to predict team level outcomes like actual turnover (Bakker, Van Emmerik \& Van Riet, 2008) and daily team financial turnover (Xanthopoulou, Bakker, Demerouti \& Schaufeli, 2009b). Finally, Dollard and Bakker (2010) constructed a model of workplace psychosocial safety climate (PSC) to explain the origins of job demands and resources, worker psychological health, and employee engagement. PSC refers to policies, practices, and procedures for the protection of worker psychological health and safety. Organisation-level PSC predicted change in individual psychological health problems (psychological distress, emotional exhaustion) through its relationship with individual job demands (work pressure and emotional demands) and moderated the relationship between emotional demands and emotional exhaustion. 
We applaud such attempts and encourage researchers to integrate multiple levels in their research using the JD-R model. This can be achieved not only by integrating predictors or outcomes from another level in the model, but also by looking whether constructs maintain their meaning across levels of analysis (i.e. isomorphic variables). It is, for instance, possible that a supportive team atmosphere is a clear resource on the individual level but on the team level it can represent a factor that restricts individual freedom. In this way, the same construct might have different functions on different levels of analysis. From a theoretical point of view, multilevel constructs result in a better understanding of psychological phenomena unfolding within organisations. From a practical point of view, knowledge gathered by following a multilevel approach can help guide the development of more effective interventions. For instance, detecting similarities or differences in the meaning of performance across levels of analysis can allow organisations to employ similar or different strategies for managing performance at the individual, group and organisational level.

\section{Diary studies}

Testing between-person variation as is performed in crosssectional and longitudinal survey research is important because it highlights how employees differ in their general reactions to work, well-being, and performance. However, it is also important to take into account that working conditions and reactions to them may vary from day to day (Butler, Grzywacz, Bass \& Linney, 2005; Simbula, 2010). Such variations may explain why employees who are engaged in their jobs sometimes have 'off-days', or why employees who are usually exhausted feel satisfied on certain days. Diary studies enable us to examine, in addition to general predictors such as stable resources specified in the JD-R model (Demerouti et al., 2001), the more proximal predictors of outcomes like state work engagement or fatigue. Thus, this approach promises answers to questions, such as: When do persons feel engaged or exhausted? Are there specific situational features that have to be present during a specific day in order to feel engaged or exhausted? Knowledge about the more proximal situational and person-related predictors of JD-R outcomes, such as state-like or daily fluctuating experiences of work engagement or burnout tendencies, is crucial to create a setting that optimally supports positive states in volatile organisational environments.

Recently, Simbula (2010) conducted the first diary study that tests the dynamic nature of the JD-R model with regard to both motivational and health impairment processes. Specifically, this study examined whether daily fluctuations in coworkers' support (i.e. a typical job resource) and daily fluctuations in work-family conflict (i.e. a typical demand) predicted day-levels of job satisfaction and mental health through work engagement and exhaustion, respectively. A total of 61 schoolteachers completed a general questionnaire and a daily survey over a period of five consecutive workdays. Consistent with the assumptions of the JD-R model, results showed that day-level work engagement mediated the impact of day-level coworkers' support on day-level job satisfaction and day-level mental health, after controlling for general levels of work engagement and the outcome variables. Moreover, day-level exhaustion mediated the relationship between day-level work-family conflict and day-level job satisfaction and day-level mental health after general levels of exhaustion and the outcome variables had been controlled for.

Thus, Simbula's (2010) study confirms that the assumptions of the JD-R model hold also on a day level. However, the findings of other diary studies do not completely overlap with those of studies using a between person approach. Although job demands have rarely been addressed as potential predictors of state-like work engagement, the diary study by Bakker, van Emmerik, Geurts, and Demerouti (2010) found that day-level workload was positively related to day-level state work engagement on days that employees felt recovered - suggesting that workload acted as a challenge stressor or demand. This means that although the assumptions of the JD-R model might apply on a longer term as well as on a daily level, the role of specific demands might be different depending on whether it is viewed from a the short-term or a long-term perspective. Daily demands can have positive effects on states like work engagement. In the longer run they may, however be damaging. Future studies are necessary to clarify such differences in proximal and distal processes in the context of the JD-R model.

\section{Linking the JD-R model with objective health indicators}

Until recently, researchers studying outcomes in the context of the JD-R model focused on interpersonal, attitudinal, and organisational consequences (Schaufeli \& Enzmann, 1998). In the past decade, however, growing evidence has pointed to the fact that outcomes like burnout have negative repercussions for health as well. Previous reviews on this topic have mainly focused on burnout and the risk to mental health (see Leiter \& Maslach, 2001; Schaufeli \& Enzmann, 1998; Shirom, 2009). Melamed et al. (2006) in their review provided accumulated evidence suggesting that burnout might also pose a risk to physicalhealth.Specifically, they provideevidencesuggesting that even after adjusting for potential confounding variables, the relative risk (RR) associated with burnout, approached, was equal to, and sometimes (depending on the outcome studied) even exceeded the risk conferred by classical risk factors, such as age, body mass index (BMI), smoking, blood pressure, and lipid levels. The authors present evidence supporting several potential mechanisms linking burnout with ill health, including metabolic syndrome, deregulation of the hypothalamic-pituitary-adrenal axis along with sympathetic nervous system activation, sleep disturbances, systemic inflammation, impaired immunity functions, and poor health behaviours. Recent studies show that burnout is also related to an increased risk of future hospitalisation due to mental and cardiovascular disorders (Toppinen-Tanner, Ahola, Koskinen \& Väänänen, 2009), and the development of musculoskeletal pain over time (Melamed, 2009). 
Other studies have reported that a lack of positive affect rather than heightened negative affect predicts mortality (Blazer \& Hybels, 2004), and the development of disability (Ostir, Markides, Black \& Goodwin, 2000) in older adults. According to Steptoe, Wardle, Marmot (2005), two sets of mechanisms could theoretically mediate the relationship between affective states and physical health. Firstly, positive well-being might be associated with favourable health habits and prudent lifestyles. For example, cigarette smoking is associated with psychological distress (Jarvis, 2002), and depression and anxiety are inversely related to leisure-time physical activity (Biddle \& Mutrie, 2001). The second possibility is that associations are mediated through psychobiological processes so that psychosocial factors might stimulate biological systems through central nervous system activation of autonomic, neuroendocrine, inflammatory, and immune responses. For instance, depression has been linked with increased levels of C-reactive protein and inflammatory cytokines (Panagiotakos et al., 2004), prolonged norepinephrine responses to stress (Gold, Zakowski, Valdimarsdottir \& Bovbjerg, 2004), and deficient immune responses after vaccination (Rosenkranz et al., 2003). Similarly, Steptoe et al. (2005) found that positive affect was inversely related to cortisol output and to heart rate throughout the day. Taken together, evidence suggests that affective outcomes of job demands and resources might be related to profiles of functioning in several biological systems and may therefore be relevant to the risk of development of physical illness. The challenge of future research is to examine not only the relationship between affective outcomes of the JD-R model and physical health but also to integrate the role of job demands and resources over time in such processes.

\section{Measurement issues}

Another important issue concerning the further development of the JD-R model is how the different components of the model should be operationalised. Specifically, is it important to develop a JD-R instrument that includes various demands, resources, health and motivational indicators and outcomes; or should the model be tested using different instruments? The first option would offer a universally applicable instrument including different components. The researcher could then select the dimensions to be measured in each specific study and depending on the focal job. For instance, whilst physical demands are relevant for a farmer, mental demands are more relevant for a teacher. Next to the high applicability, such an instrument has the advantage that it would facilitate the comparison of mean scores between different job functions and organisations. The use of different instruments in the various studies to capture demands and resources or the outcomes of the JD-R model has the advantage that the flexibility of the model is increased as different dimensions can be measured than those included in a universal instrument. Moreover, the validity of the model is underscored when the model assumptions are confirmed using different measurement instruments. With the increasing popularity of the model, future researchers and practitioners will be confronted with this dilemma even more often, and the answer could be somewhere in the middle, that is, the combination of both options.

\section{Answering the question 'How high is high?'}

When conducting studies with the JD-R framework, organisations and employees are very interested to know whether the specific demands and resources are on such a risk level that they should undertake action. This question cannot be answered with the correlational analyses that are typically conducted with such studies. Whilst a researcher is interested in uncovering effects and relationships between variables (how high is the impact of A on B?), organisations need to know whether they are doing well or not (whether their score on A is high). Future researchers cannot ignore this need of organisations and should try to integrate the issue of cut-off scores of job demands and job resources in their research. There are several ways to achieve this. One way is to integrate odds ratios in the analysis. The odds ratio is the ratio of the odds in favour of getting the disease, if exposed, to the odds in favour of getting a disease, if not exposed (Ogunbanjo, 2004). In other words, it is a measure of association, which quantifies the relationship between an exposure and health outcome from a comparative study. The odds of an event are the probability of it occurring compared to the probability of it not occurring. Reporting the odds ratio or relative risk as a measure of association is typical in epidemiologic studies of etiologic risk factors and is now common in studies of predictive markers as well, although this is not without criticism (Pepe, Janes, Longton, Leisenring, Polly \& Newcomb, 2004). Although the odds ratio does not characterise a marker's accuracy for classifying persons, its association with the relative risk has long made it valuable for characterising population variations in risk. A binary marker with a relative risk of 3, for example, can be used to identify a population with the risk factor that has three times the risk as the population without the risk factor. This method may be used to target prevention or screening strategies.

A second and related way is to conduct a clinical validation study. This method was applied by Schaufeli et al. (2001) to investigate the clinical validity of the MBI burnout measure (Maslach et al., 1996). More specifically, the authors compared the scores of a group of 'burned out' outpatients from a psychotherapeutic treatment centre specialised in work-related problems with a comparison 'nonburned out' group who was on treatment for problems other than burnout (e.g. panic disorders, or obsessive-compulsive disorder etc.) as well as with a sample of employees from different organisations. Based on the scores of the burnedout group, clinically validated empirical cut-off points could be determined for the Dutch version of the MBI instrument (Schaufeli \& van Dierendonck, 2000). Such methodology could be extended and applied to uncover the meaningful cut-off scores for the job demands and job resources so that the critical risk values are recognised and highlighted. 


\section{Job crafting}

Studies on the JD-R model have consistently shown that employees show the best job performance in challenging, resourceful work environments because such environments facilitate their work engagement (Bakker \& Bal, 2010; Demerouti \& Cropanzano, 2010). This implies that organisations should offer their employees sufficient job resources, including feedback, social support, and skill variety. Research indeed suggests that management can influence employees' job demands and resources (Nielsen, Randall, Yarker \& Brenner, 2008), and may indirectly influence employee engagement and performance (Tims, Bakker \& Xanthopoulou, in press).

However, it may be equally important that employees mobilise their own job resources. Managers are not always available for feedback, and organisations that are confronted with economic turmoil may set other priorities. Under such conditions, it may be particularly important for employees to mobilise their own resources, and to show proactive behaviour. Parker and Ohly (2008) have argued that employees may actively change the design of their jobs by choosing tasks, negotiating different job content, and assigning meaning to their tasks or jobs. This process of employees shaping their jobs has been referred to as job crafting (Wrzesniewski \& Dutton, 2001). Job crafting is defined as the physical and cognitive changes individuals make in their task or relational boundaries. Physical changes refer to changes in the form, scope or number of job tasks, whereas cognitive changes refer to changing how one sees the job.

Tims, Bakker and Derks (2010) recently defined job crafting as the changes employees may make regarding their job demands and job resources. This conceptualisation takes the JD-R model (Demerouti et al., 2001) as a starting point. According to Tims and her colleagues, job crafting can take the form of three different types of behaviours: increasing (structural or social) job resources; increasing job demands or challenges; and decreasing job demands. They argued that employees who optimise their work environment would report the highest levels of engagement. It would be very interesting to integrate job crafting in the JD-R model. It can be hypothesised that job crafting is the missing link in the reversed causal path from work engagement to future job demands and job resources (Bakker, in press).

\section{Overview of articles in this special issue}

This special issue includes a selected number of interesting articles that each tap into new directions in which research on Job Demands-Resources model might go. Idris, Dollard and Winefield expand the JD-R model by proposing psychosocial safety climate (PSC) as a precursor to job demands and job resources. As PSC theoretically influences the working environment, the authors hypothesise that PSC has an impact on performance via both health erosion (i.e. burnout) and motivational pathways (i.e. work engagement). This study was conducted in Malaysia, amongst 291 employees. Results indicated that PSC was negatively related to job demands and positively related to job resources. Job demands, in turn, predicted burnout (i.e. exhaustion and cynicism), whereas job resources predicted engagement. Both burnout and engagement were associated with performance. These findings suggest that JD-R model may be expanded to include PSC as an antecedent, and that the expanded JD-R model is largely valid in an Eastern, developing economy setting.

Schreurs, De Cuyper, Van Emmerik, Notelaers and De Witte examine the mechanisms through which job characteristics associate with early retirement intention, using the JD-R model as a theoretical framework. Two parallel processes were theorised to shape early retirement intention: a health impairment process (i.e. job demands $\rightarrow$ recovery need $\rightarrow$ early retirement intention) and a motivational process (i.e. job resources $\rightarrow$ work enjoyment $\rightarrow$ early retirement intention). Survey data were collected from a heterogeneous sample of 1812 older workers (age $>45$ ). Results showed that job demands and job resources were both associated with work enjoyment, which was associated with early retirement intention. Recovery need did not add to the prediction of early retirement intention. This study suggests that - for early retirement intention - the motivational process is more prominent than the health impairment process.

Van den Broeck, Baillien, and De Witte aim to extend the outcomes examined in the JD-R model to a specific form of counterproductive interpersonal behaviour: workplace bullying. They expected job demands and job resources to relate to both perpetrators' and actors' reports of workplace bullying. Using questionnaire data of 749 Flemish employees they found that neither job demands nor job resources showed a main effect on perpetrators' reports of bullying. Job demands and job resources however interacted: rather unexpectedly, the positive association between job demands and perpetrators' reports of bullying was particularly strong under the condition of high job resources. Furthermore, job demands related positively to targets' reports of bullying, and job resources negatively. Emotional exhaustion (partially) mediated these associations. These results suggest that workplace bullying may indeed be reduced by good job design, that is, by limiting the job demands and increasing job resources.

De Braine and Roodt explore possible differences in the JD-R model as predictor of overall work engagement, dedication only and work-based identity, through comparative predictive analyses. A survey was conducted amongst a population of 2429 employees. The JD-R model explained a greater amount of variance in dedication than in work engagement. It, however, yielded the greatest amount of explained variance in work-based identity, with job resources being its strongest predictor. Managing job resources and demands can improve identification and work engagement levels. This study builds on the literature of the JD-R model by showing that it can be used to predict work-based identity. 
Doosje, De Goede, Van Doornen and Van Den Schoot extend our understanding of the role of traditional variables like job demands and job control with humorous coping styles and affective variables with regard to the explanation of the frequency of upper respiratory tract infection (URTI). Using a sample of 2094 employees they found that job demands were indirectly related to the frequency of URTI, mediated by their relationships with job control and negative job-related affect. Generic and response-focused humorous coping were less relevant for the explanation of the frequency of URTI than the presumably 'healthy' antecedent-focused humorous coping style. The latter showed a negative association with negative job-related affect. The frequency of URTI was better predicted by job control and negative job-related affect than by humorous coping. Although it was shown that healthy humorous coping does contribute to decreases in URTI; job demands, job resources and negative affective state seem the most important predictors.

Finally, Tremblay and Messervey examine the role of compassion satisfaction, conceptualised as a personal resource, in buffering the relationship between job demands and job strain. Accordingly, four demanding aspects of the job (i.e. role overload, insufficiency, ambiguity, and conflict) and one personal resource (i.e. compassion satisfaction) were used to test the central hypothesis that the interaction between (high) job demands and (low) personal resources produces the highest levels of anxiety and depression as indicators of job strain. The authors tested these hypotheses amongst 122 military chaplains. Results showed that compassion satisfaction moderated the relationship between job demands and job strain. More specifically, when compassion satisfaction was high, the effect of role overload on job strain was significantly reduced. However, the relationships between the other three role stressors and job strain were not offset by compassion satisfaction.

We hope that this special issue will inspire and encourage researchers to expand their research horizon to conduct research within the Job Demands-Resources model.

\section{References}

Avey, J.M., Luthans, F., \& Jensen, S. M. (2009). Psychological capital: A positive resource for combating employee stress and turnover. Human Resource Management, 48, 677-693. doi:10.1002/hrm.20294

Bakker, A.B. (2010). Engagement and job crafting: Engaged employees create their own great place to work. In S. Albrecht (Ed.), Handbook on employee engagement own great place
(pp. 229-244).

Bakker, A.B., \& Bal, P.M. (2010). Weekly work engagement and performance: A study among starting teachers. Journal of Occupational and Organisational Psychology, 83, 189-206. doi:10.1348/096317909X402596

Bakker, A.B., \& Demerouti, E. (2007). The Job Demands-Resources model: State of the art. Journal of Managerial Psychology, 22, 309-328.

Bakker, A.B., Demerouti, E., \& Euwema, M.C. (2005). Job resources buffer the impact of job demands on burnout. Journal of Occupational Health Psychology, 10, 170180. doi:10.1037/1076-8998.10.2.170, PMid:15826226

Bakker, A.B., Demerouti, E., De Boer, E., \& Schaufeli, W.B. (2003a). Job demands and job resources as predictors of absence duration and frequency. Journal of Vocational Behavior, 62, 341-356. doi:10.1016/S0001-8791(02)00030-1

Bakker, A.B., Demerouti, E., \& Schaufeli, W.B. (2003). Dual processes at work in a call centre: An application of the Job Demands - Resources model. European Journal of Work and Organizational Psychology, 12, 393-417. doi:10.1080/13594320344000165

Bakker, A.B., Demerouti, E., Taris, T., Schaufeli, W.B., \& Schreurs, P. (2003). A multigroup analysis of the Job Demands - Resources model in four home care organisations. International Journal of Stress Management, 10, 16-38. doi:10.1037/1072 5245.10.1.16
Bakker, A.B., Van Emmerik, H., \& Van Riet, P. (2008). How job demands, resources, and burnout predict objective performance: A constructive replication. Anxiety, Stress, and Coping, 21, 309-324. doi:10.1080/10615800801958637

Bakker, A.B., Van Emmerik, H., Demerouti, E., \& Geurts, S. (2010). Recovery turns job demands into challenges: A diary study on work engagement and performance. Unpublished manuscript.

Bakker, A.B., Van Veldhoven, M.J.P.M., \& Xanthopoulou, D. (2010). Beyond the Demand-Control model: Thriving on high job demands and resources. Journal of Personnel Psychology, 9, 3-16. doi:10.1027/1866-5888/a000006

Baumeister, R.F., \& Leary, M.R. (1995). The need to belong: Desire for interpersonal attachments as a fundamental human motivation. Psychological Bulletin, 117 497-529. doi:10.1037/0033-2909.117.3.497, PMid:7777651

Biddle, S.J.H., \& Mutrie, N. (2001). Psychology of physical activity. London: Routledge.

Blazer, D.G., \& Hybels, C.F. (2004). What symptoms of depression predict mortality in community-dwelling elders? Journal of the American Geriatrics Society, 52, 2052-2056. doi:10.1111/j.1532-5415.2004.52564.x, PMid:15571541

Butler, A.B., Grzywacz, J.G., Bass, B.L., \& Linney, K.D. (2005). Extending the demandscontrol model: A daily diary study of job characteristics, work-family conflict and work-family facilitation. Journal of Occupational and Organizational Psychology, 78, 155 -169. doi:10.1348/096317905X40097

Cavanaugh, M.A., Boswell, W.R., Roehling, M.V., \& Boudreau, J.W. (2000). An empirical examination of self-reported work stress among U.S. managers. Journal of Applied Psychology, 85, 65-74. doi:10.1037/0021-9010.85.1.65, PMid:10740957

Chen, G., Mathieu, J.E., \& Bliese, P.D. (2004) A Framework for Conducting Multilevel Construct Validation. In F.J. Dansereau \& F. Yamarino (eds.). Research in Multilevel Issues: Multilevel Issues in Organizational Behavior and Processes vol. 3, (pp. 273-303). Elsevier: Oxford UK.

Costa Jr, P.T., \& McCrae, R.R. (1990). Personality disorders and the five-factor model of personality. Journal of Personality Disorders, 4, 362-371.

DeCharms, R. (1968). Personal causation. New Jersey: Lawrence Erlbaum Associates.

Deci, E.L., \& Ryan, R.M. (1985). Intrinsic motivation and self-determination in human behavior. New York: Plenum Press.

Demerouti, E., Bakker, A.B., Nachreiner, F., \& Schaufeli, W.B. (2000). A model of burnout and life satisfaction among nurses. Journal of Advanced Nursing, 32, 454-464.

Demerouti, E., \& Cropanzano, R. (2010). From thought to action: Employee work engagement and job performance. In A.B. Bakker \& M.P. Leiter (Eds.), Work engagement: $A$ handbook of essential theory and research (pp. 147-163). New York: Psychology Press.

Demerouti, E., Bakker, A.B., Nachreiner, F., \& Schaufeli, W.B. (2001). The job demandsresources model of burnout. Journal of Applied Psychology, 86, 499-512. resources model of burnout. Journal of Applied
doi:10.1037/0021-9010.86.3.499, PMid:11419809

Dollard, M.F., \& Bakker, A.B. (2010). Psychosocial safety climate as a precursor to conducive work environments, psychological health problems, and employee engagement Journal of Occupational and Organizational Psychology, 83, 579599. doi:10.1348/096317909X470690

Drazin, R., Glynn, M.A., \& Kazanjian, R.K. (1999). Multilevel theorizing about creativity in organizations: A sensemaking perspective. Academy of Management Review, 24, 286-307. doi:10.2307/259083

George, J.M. (1990) Personality, affect, and behaviour in groups. Journal of Applied Psychology, 75, 107-116. doi:10.1037/0021-9010.75.2.107

Gold, S.M., Zakowski, S.G., Valdimarsdottir, H.B., \& Bovbjerg, D.H. (2004). Higher Beck depression scores predict delayed epinephrine recovery after acute psychological stress independent of baseline levels of stress and mood. Biological Psychology, 67, 261-273. doi:10.1016/j.biopsycho.2003.12.001, PMid:15294385

Hackman, J. R., \& Oldham, G.R. (1980). Work redesign. Reading, MA: Addison-Wesley.

Hakanen, J.J., Bakker, A.B., \& Demerouti, E. (2005). How dentists cope with their job demands and stay engaged: The moderating role of job resources. European Journal of Oral Sciences, 113, 479-487. doi:10.1111/j.1600-0722.2005.00250.x, PMid:16324137

Hobfoll, S.E. (2001). The influence of culture, community, and the nested-self in the stress process: Advancing conservation of resources theory. Applied Psychology: An International Review, 50, 337-370. doi:10.1111/1464-0597.00062

Hobfoll, S.E. (2002). Social and psychological resources and adaptation. Review of General Psychology, 6, 307-324. doi:10.1037/1089-2680.6.4.307

Hockey, G.R.J. (1993). Cognitive-energetical control mechanisms in the management of work demands and psychological health. In A. Baddely \& L. Weiskrantz (Eds.) Attention: Selection, awareness, and control (pp. 328-345). Oxford: Clarendon Press.

Jarvis, M. (2002) Smoking and stress. In S.A. Stansfeld, \& M. Marmot (eds.), Stress and the Heart (pp. 150-157). London: BMJ Books.

Karasek, R.A. (1998). Demand/Control Model: A social, emotional, and physiological approach to stress risk and active behaviour development. In J.M. Stellman (Ed.) Encyclopaedia of occupational health and safety (pp. 34.6-34.14). Geneva: ILO.

Lazarus, R.S., \& Folkman, S. (1984). Stress, appraisal, and coping. New York: Springer.

Leiter, M.P. (1993). Burnout as a developmental process: Consideration of models. In W.B. Schaufeli, C. Maslach \& T. Marek (Eds.), Professional burnout: Recent developments in theory and research (pp. 237-250). Washington, DC: Taylor \& Francis.

Leiter, M.P., \& Maslach, C. 2001. Burnout and quality in a speed-up world. Journal for Quality \& Participation, 24, 48-51.

LePine, J.A., Podsakoff, N.P., \& LePine, M.A. (2005). A meta-analytic test of the challenge stressor-hindrance stressor framework: An explanation for inconsistent relationships among stressors and performance. Academy of Management Journal, 48, 764-775. 
Lewig, K., Xanthopoulou, D., Bakker, A.B., Dollard, M., \& Metzer, J. (2007). Burnout and connectedness among Australian volunteers: A test of the Job DemandsResources model. Journal of Vocational Behavior, 71, 429-445. doi:10.1016/j. Resources model.
jvb.2007.07.003

Lindsley, D.H., Brass, D.J., \& Thomas, J.B. (1995) Efficacy-performance spirals: A multilevel perspective. Academy of Management Review, 20, 645-678. doi:10.2307/258790

Maslach, C., Jackson, S.E., \& Leiter, M.P. (1996). MBI: The Maslach Burnout Inventory: Manual. Palo Alto: Consulting Psychologists Press.

McCauley, C.D., Ruderman, M.N., Ohlott, P.J., \& Morrow, J.E. (1994). Assessing the developmental components of managerial jobs. Journal of applied psychology, 79 544-560. doi:10.1037/0021-9010.79.4.544

Meijman, T.F., \& Mulder, G. (1998). Psychological aspects of workload. In P.J. Drenth, H. Thierry, \& C.J. de Wolff (Eds.), Handbook of Work and Organisational Psychology (2nd ed.; pp. 5-33). Hove, UK: Erlbaum

Melamed, S. (2009). Burnout and risk of regional musculoskeletal pain: A prospective study of apparently healthy employed adults. Stress and Health, 25, 313- 321 doi:10.1002/smi.1265

Melamed, S., Shirom, A., Toker, S., Berliner, S., \& Shapira, I. (2006). Burnout and risk of cardiovascular disease: Evidence, possible causal paths, and promising research directions. PsychologicalBulletin,132,327-353. doi:10.1037/0033-2909.132.3.327 PMid:16719565

Nielsen, K., Randall, R., Yarker, J., \& Brenner, S.O. (2008). The effects of transformational leadership on followers' perceived work characteristics and
psychological well-being: A longitudinal study. Work \& Stress, 22, 16-32. psychological well-being: A longi
doi:10.1080/02678370801979430

Ogunbanjo, G.A. (2004). Making sense of statistics for family practitioners: 'What is odds ratio?' South African Family Practice, 46, 44.

Ostir, G.V., Markides, K.S., Black, S.A., \& Goodwin, J.S. (2000). Emotional wellbeing predicts subsequent independent functioning and survival. Journal of the being predicts subsequent independent func
American Geriatrics Society, 48, 473-478.

Panagiotakos, D.B., Pitsavos, C., Chrysohoou, C., Tsetsekou, E., Papageorgiou, C., Christodoulou, G., \& Stefanadis, C. (2004). Inflammation, coagulation, and depressive symptomatology in cardiovascular disease-free people; the ATTICA study. European. Heart Journal, 25, 492-499. doi:10.1016/j.ehj.2004.01.018, PMid:15039129

Parker, S.K., \& Ohly, S. (2008). Designing motivating jobs. In R. Kanfer, G. Chen \& R Pritchard (Eds.), Work motivation: Past, present, and future (pp. 233-284). SIOP Organizational Frontiers Series.

Pepe, M.S., Janes, H., Longton, G., Leisenring, W., \& Newcomb, P. (2004). Limitations of the odds ratio in gauging the performance of a diagnostic, prognostic, or
screening marker. American Journal of Epidemiology, 159, 882-890. doi:10.1093/ aje/kwh101, PMid:15105181

Podsakoff, N.P., LePine, J.A., \& LePine, M.A. (2007). Differential challenge stressorhindrance stressor relationships with job attitudes, turnover intentions, turnove and withdrawal behavior: A meta-analysis, Journal of Applied Psychology, 92, 438-454. doi:10.1037/0021-9010.92.2.438, PMid:17371090

Riolli, L., \& Savicki, V. (2003). Optimism and coping as moderators of the relationship between work resources and burnout in information service workers. International Journal of Stress Management, 10, 235-252. doi:10.1037/1072-5245.10.3.235

Rosenkranz, M.A., Jackson, D.C., Dalton, K.M., Dolski, I., Ryff, C.D., Singer, B.H., Muller, D., Kalin, N.H., \& Davidson, R.J. (2003). Affective style and in vivo immune response: Neurobehavioral mechanisms. Proceedings of the National Academy of Sciences of the United States of America, 100, 11148-11152. doi:10.1073/ pnas.1534743100, PMid:12960387, PMCid:196942

Schaufeli, W.B., \& Bakker, A.B. (2004). Job demands, job resources, and their relationship with burnout and engagement: A multi-sample study. Journal of Organizational Behavior, 25, 293-315.
Schaufeli, W.B., Bakker, A.B., Schaap, C., Kladler, A., \& Hoogduin, C.A.L. (2001). On the clinical validity of the Maslach Burnout Inventory and the Burnout Measure. Psychology \& Health, 16, 565-582. doi:10.1080/08870440108405527

Schaufeli, W.B., Bakker, A.B., \& Van Rhenen, W. (2009). How changes in job demands and resources predict burnout, work engagement, and sickness absenteeism. Journal of Organizational Behavior, 30, 893-917. doi:10.1002/job.595

Schaufeli, W.B., \& Enzmann, D. (1998). The burnout companion to study and practice: A critical analysis. Washington, DC: Taylor \& Francis.

Schaufeli, W.B., \& Van Dierendonck, D. (2000). UBOS-Utrechtse Burnout Schaal. Handleiding [UBOS-Test Manual]. Lisse. The Netherlands: Swets Test Services.

Shirom, A. (2009). Editorial; Burnout and health: Expanding our knowledge. Stress and Health, 25, 281-285. doi:10.1002/smi.1283

Shirom, A. (2009). Epilogue: mapping future research on burnout and health. Stress and Health, 25, 375-380. doi:10.1002/smi.1284

Siegrist J. (1996). Adverse health effects of high effort-low reward conditions. Journal of Occupational Health Psychology, 1, 27-41. doi:10.1037/1076-8998.1.1.27, PMid:9547031

Simbula, S. (2010). Daily fluctuations in teachers' well-being: A diary study using the Job Demands-Resources model. Anxiety, Stress \& Coping: An International Journal, 23, 563-584.

Steptoe, A., Wardle, J., \& Marmot, M. (2005). Positive affect and health-related neuroendocrine, cardiovascular, and inflammatory processes. Proceedings of the National Academy of Sciences, 102, 6508-6512. doi:10.1073/pnas.0409174102 PMid:15840727, PMCid:1088362

Tims, M., Bakker, A.B., \& Derks, D. (2010). The development and validation of the job crafting scale. Manuscript submitted for publication.

Tims, M., Bakker, A.B., \& Xanthopoulou, D. (in press). Do transformational leaders enhance their followers' work engagement? The Leadership Quarterly.

Toppinen-Tanner, S., Ahola, K., Koskinen, A., \& Väänänen, A. (2009). Burnout predicts hospitalization for mental and cardiovascular disorders: 10-year prospective results from industrial sector. Stress and Health, 25, 287-296. doi:10.1002/ results from
smi.1282

Van den Broeck, A., Vansteenkiste, M., De Witte, H., \& Lens, W. (2008). Explaining the relationships between job characteristics, burnout and engagement: The role of basic psychological need satisfaction. Work \& Stress, 22, 277-294.

Van den Broeck, A., De Cuyper, N., De Witte, H., \& Vansteenkiste, M. (in press). Not al job demands are equal: Differentiating job hindrances and job challenges in the Job Demands-Resources model. European Journal of Work and Organizational Psychology. doi:10.1080/02678370802393672

White, R. (1959). Motivation reconsidered: The concept of competence. Psychological Review, 66, 297-333. doi:10.1037/h0040934, PMid:13844397

Wrzesniewski, A., \& Dutton, J. E. (2001). Crafting a job: Revisioning employees as active crafters of their work. Academy of Management Review, 26, 179-201. doi:10.2307/259118

Xanthopoulou, D. Bakker, A.B., Demerouti, E., \& Schaufeli, W.B. (2009a). Reciprocal relationships between job resources, personal resources, and work engagement. Journal of Vocational Behavior, 74, 235-244. doi:10.1016/j.jvb.2008.11.003

Xanthopoulou, D., Bakker, A.B., Demerouti, E., \& Schaufeli, W.B. (2009b). Work engagement and financial turnover: A diary study on the role of job and personal resources. Journal of Occupational and Organizational Psychology, 82, 183-200. doi:10.1348/096317908X285633

Xanthopoulou, D., Bakker, A.B., Demerouti, E., Schaufeli, W.B. (2007a). The role of personal resources in the job demands-resources model. International Journal of Stress Management, 14, 121-141. doi:10.1037/1072-5245.14.2.121

Xanthopoulou, D., Bakker, A.B., Dollard, M.F., Demerouti, E., Schaufeli, W.B., Taris, T.W. \& Schreurs, P.J.G. (2007b). When do job demands particularly predict burnout? The moderating role of job resources. Journal of Managerial Psychology, 22, 766786. doi:10.1108/02683940710837714 